\title{
VALORES HUMANOS E INTERESSES VOCACIONAIS: UM ESTUDO CORRELACIONAL ${ }^{1}$
}

\author{
Valdiney Veloso Gouveia* \\ Maja Meira \\ Estefânea Élida da Silva Gusmão\# \\ Marcílio Lira de Souza Filho\# \\ Luana Elayne Cunha de Souza"
}

\begin{abstract}
RESUMO. Este estudo teve como objetivo principal identificar em que medida os interesses vocacionais dos adolescentes se relacionam com os valores que indicam como prioritários em suas vidas. Para alcançar este objetivo contou-se com a participação de 307 estudantes do ensino médio (público e privado) de João Pessoa (PB), com idade média de 16 anos $(D P=$ 1,60). Os participantes responderam ao Inventário de Interesse Vocacional (UNIACT) e ao Questionário dos Valores Básicos $(Q V B)$. Os resultados demonstraram que os interesses vocacionais e os valores humanos estão correlacionados. Tais achados são discutidos em função das congruências entre as características descritoras de ambos os construtos.
\end{abstract}

Palavras-chave: valores humanos, interesses vocacionais, adolescentes.

\section{HUMAN VALUES AND VOCATIONAL INTERESTS: A CORRELATED ANALYSIS}

\begin{abstract}
The manner students' vocational interests are linked to their value priorities is analyzed. Participants comprised 307 undergraduate students, mean age 16 years $(S D=1.60)$, from private and public schools of João Pessoa PB Brazil. They answered the Vocational Interest Inventory (UNIACT), Basic Value Survey (BVS), and demographic questions. Results show correlations between vocational interests and human values. These findings may be discussed as a result of the congruencies among the descriptive traits of the two constructs.
\end{abstract}

Key words: Human values, vocational interests, adolescents.

\section{INTERESES VOCACIONALES Y VALORES HUMANOS: UN ESTUDIO CORRELACIONAL}

RESUMEN. Este estudio tuvo como objetivo principal identificar en qué medida los intereses vocacionales de los adolescentes se relacionan con los valores que éstos indican como prioritarios en sus vidas. Para lograr este objetivo, se ha tenido en cuenta una muestra de 307 estudiantes de bachillerato (escuelas públicas y privadas) de João Pessoa (PB), con edad promedia de 16 años $(\mathrm{DT}=1.60)$. Los participantes contestaron al Inventario de Interés Vocacional (UNIACT) y al Cuestionario de los Valores Básicos (CVB). Los resultados indicaron que los intereses vocacionales y los valores humanos están correlacionados. Estos hallazgos son discutidos de acuerdo con las congruencias entre las características descriptoras de ambos constructos..

Palabras-clave: Valores humanos, intereses vocacionales, adolescentes.

Os interesses vocacionais que as pessoas manifestam têm alguma relação com as prioridades que elas dão aos valores que lhes guiam a vida? Embora a resposta a respeito pareça óbvia, uma vez que os interesses em si estão intrinsecamente relacionados com os valores humanos (Holland, 1997; Rokeach, 1973; Schwartz \& Bilsky, 1987), isso não é tão evidente. Neste sentido, o objetivo do presente

\footnotetext{
1 Apoio: $\mathrm{CNPq}$.

* Doutor em Psicologia Social. Docente da Universidade Federal da Paraíba.

\# Mestre em Psicologia.

II Graduanda em Psicologia pela Universidade Federal da Paraíba.
} 
estudo é conhecer em que medida os interesses vocacionais dos adolescentes se relacionam com os valores que indicam como prioritários em suas vidas. Poucas pesquisas empíricas têm sido efetivamente realizadas enfocando diretamente a correlação entre estes dois construtos. Uma exceção compreende o estudo levado a cabo por Sagiv (2002), que considerou jovens adultos israelenses submetidos a um serviço de aconselhamento profissional em Israel.

A necessidade de estudos na área dos interesses vocacionais teve sua gênese nas grandes rupturas sociais, tecnológicas e econômicas. O advento das duas Grandes Guerras, a necessidade de aumentar a produtividade da indústria, o desemprego dos anos 1930, a Psicanálise, dentre outros fatores, desembocaram, duas décadas depois, em uma série de teorias que tratavam do tema. Estas teorias podem ser classificadas em três grupos distintos: um integra as teorias não psicológicas (econômicas, culturais, sociológicas etc.); o segundo, as psicológicas (teorias de personalidade, psicanalíticas e do eu); e o terceiro integra as teorias mais gerais (tipologias estruturadas). Estas têm como um dos autores mais conhecidos e influentes John L. Holland (Giacaglia, 2003), cujo modelo será mais adiante considerado.

Não obstante, no Brasil, o estudo dos interesses vocacionais tem se guiado, principalmente, por uma ênfase em abordagens psicodinâmicas, de cunho predominantemente clínico, procurando conhecer, por exemplo, o papel da presença dos pais, da perda parental ou de sua ausência e do contexto familiar na orientação profissional. Um exemplo desta tendência é expresso no livro Orientação Vocacional Ocupacional, organizado por Levenfus e Soares (2002). O presente estudo trilha outro caminho, interessando-lhe contribuir com dados empíricos para o campo dos interesses vocacionais, porquanto não tem sido até o momento esta a ênfase dos trabalhos realizados na temática (ver Gouveia, Meira, Gusmão, Gouveia \& Pessoa, no prelo). Para o estudo dos interesses vocacionais, considerou-se o modelo teórico descrito a seguir.

\section{O MODELO RIASEC DOS INTERESSES VOCACIONAIS}

Holland (1997) propôs uma teoria a respeito das personalidades vocacionais que tem sido aplicada com sucesso na prática de psicólogos, conselheiros e orientadores vocacionais na atualidade (Day \& Rounds, 1998; Giacaglia, 2003; Weinrach, 1996). Esse autor delineou inicialmente sua teoria da escolha vocacional em 1959, e desde então diversos estudos vêm sendo realizados em vários países, tendo sido comprovado seu modelo inclusive no Brasil (Gouveia et al., no prelo). Seus esforços incluíram o desenvolvimento de instrumentos psicométricos que avaliam em que medida a pessoa endossa um ou mais dos seis tipos básicos de personalidade (Ferreira \& Hood, 1995). Segundo Day e Rounds (1998), sua teoria sobre os tipos de personalidade e os ambientes de trabalho tem dominado o campo desde sua criação, despertando grande interesse internacional tanto entre praticantes e conselheiros vocacionais como nos pesquisadores interessados por esta temática.

Holland (1996, 1997) postula classificar os interesses vocacionais de acordo com seis tipos de personalidade e/ou de ambiente. A nomenclatura RIASEC, que dá nome ao modelo, deriva da letra inicial de cada um dos tipos de personalidade postulados por Holland (1997). Para esse autor, é possível identificar empiricamente cada tipo de personalidade nos questionários que procuram medi-los, e estes se estruturam ou são representados de acordo com um hexágono, como mostrado na Figura 1.

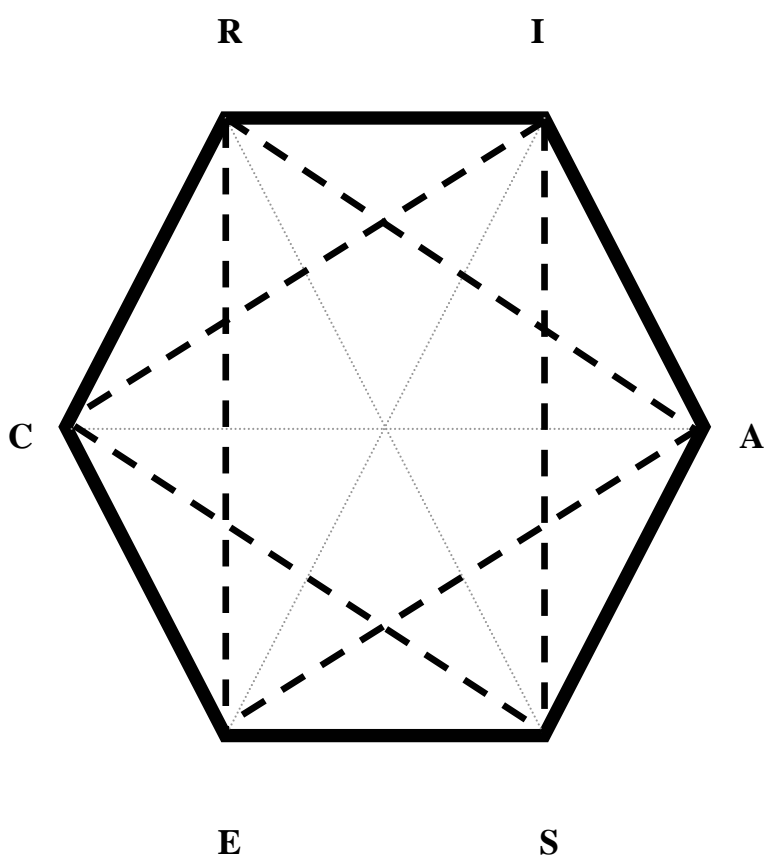

Figura 1. Modelo Hexagonal dos Interesses Vocacionais.

Esta figura expressa na realidade as relações dinâmicas que se estabelecem entre os tipos de personalidade (Farh, Leong \& Law, 1998; Holland, 1996). As linhas contínuas expressam alta consistência; as com pontilhados maiores denotam uma menor consistência e as que apresentam um pontilhado mais fraco indicam pouca ou nenhuma consistência. Operacionalmente, a consistência vem dada pela correlação entre um tipo de personalidade e 
outro. Destarte, para tipos adjacentes, como realístico e investigativo ou investigativo e artístico, esperar-seiam correlações mais fortes, enquanto entre aqueles em lados opostos - por exemplo, realístico e social ou investigativo e empreendedor -, comprovar-se-iam correlações mais fracas. Já entre tipos de personalidade alternados, como realístico e artístico, haveria uma correlação intermediária. Este esquema de consistências tem uma implicação prática, isto é, indica que pode ser menos perturbador ou menos conflitante migrar entre tipos de personalidade adjacentes, ao passo que o contrário ocorreria quando a mudança de interesse fosse verificada para aqueles que aparecem em lados opostos da figura.

Holland (1997) afirma que as pessoas com determinado tipo de personalidade se sentiriam mais confortáveis em trabalhar em um ambiente que maximizasse seus valores, sua visão de mundo e suas práticas diárias. Em outras palavras, a compatibilidade, isto é, a congruência entre tipo de personalidade e ambiente, produziria o máximo bemestar subjetivo e proporcionaria, por extensão, melhor desempenho e maior produtividade no trabalho. Os tipos de personalidade e/ou de ambiente postulados por esse autor podem ser expressos resumidamente como apresentados a seguir (Day \& Rounds, 1998; Holland, 1997). Os achados acerca dos valores e destes tipos de personalidade provêm do estudo de Sagiv (2002).

Realístico $(R)$. A pessoa que apresenta este tipo de personalidade tem preferência por atividades ordenadas, com manipulação sistemática de objetos, máquinas, ferramentas e animais, apresentando aversão a atividades educacionais e terapêuticas. Estas tendências levam à aquisição de competências manuais, mecânicas, agrícolas, elétricas e técnicas. Neste sentido, a pessoa pode ser definida como prática, conservadora, franca, inflexível, persistente e conformada. De acordo com Sagiv (2002), este tipo não apresenta claro padrão correlacional com os valores, porquanto representa motivações diferentes para pessoas diferentes, sem relações sistemáticas com qualquer tipo de valor.

Investigativo (I). Quem apresenta este tipo de personalidade prefere atividades de observação, simbólicas, sistemáticas, investigação criativa de fenômenos físicos, biológicos e culturais para entendêlos e controlá-los, assim como é avesso a atividades persuasivas, sociais e repetitivas. Tem também características analíticas, intelectuais, céticas, pessimistas, críticas, complexas, curiosas e talento acadêmico, mas poucas habilidades interpessoais, podendo ser definido como não-popular. Tal pessoa expressa uma motivação para entender aspectos abstratos e profundos do Universo, além de ser motivada por autonomia. Este tipo de personalidade relaciona-se positivamente com os valores autodireção e universalismo, fazendo-o negativamente com conformidade, segurança e tradição.

Artístico (A). Os que são caracterizados por este tipo de personalidade têm preferência por atividades ambíguas, livres e não-sistemáticas, com a manipulação de materiais verbais, físicos ou humanos. Costumam ser abertos à experiência, inovadores, desordenados, emocionais, expressivos, idealistas, independentes, introspectivos, originais, sensíveis e intelectuais, todavia com poucas habilidades clericais ou de negócios. Existe nestas pessoas um sentido forte de independência e tolerância em relação às diferenças. Assim como o tipo anterior, neste, valores como autodireção e universalismo correlacionaram-se positivamente, enquanto conformidade, segurança e tradição o fizeram negativamente.

Social $(S)$. Este tipo de personalidade indica alguém que opta por atividades que envolvem outras pessoas com aversão a atividades ordenadas, sistemáticas ou que impliquem a manipulação de materiais físicos, ferramentas e máquinas. A pessoa é empática, paciente, cooperativa, amigável, persuasiva, compreensiva, responsável e possuem habilidades interpessoais, mas poucas habilidades mecânicas. Ademais, estas preferências refletem uma motivação para cuidar dos outros. Neste tipo de personalidade foi observada uma correlação positiva com o tipo motivacional benevolência.

Empreendedor $(E)$. Quem apresenta este tipo de personalidade prefere atividades que evidenciem a "manipulação" dos outros para obter ganhos pessoais, seja no plano econômico seja no organizacional. Demonstra igualmente pouco interesse por atividades simbólicas e sistemáticas. Prima pela aquisição de competências de liderança, interpessoais e persuasivas, com habilidades de vendas e de persuasão, mas com poucas habilidades científicas. Tal pessoa apresenta como características principais ser enérgica, agradável, dominadora, ambiciosa, falante, otimista e autoconfiante. Poder e realização, positivamente, e universalismo, negativamente, foram os valores que se mostraram correlacionados com este tipo de personalidade.

Convencional $(C)$. Este tipo de personalidade é típico de pessoas que têm preferência por atividades ordenadas, de manipulação sistemática de dados, de manutenção de arquivos, reprodução de materiais, organização de relatórios, numeração de dados de acordo com planos prescritos, operação de máquinas 
de caixa, evitando atividades ambíguas, livres ou nãosistemáticas. Tais pessoas preferem desenvolver competências computacionais, clericais e de negócios, mas têm pouco interesse em atividades artísticas. Além disso, refletem a motivação para se envolver com o familiar e evitar o novo, o diferente, resistindo a mudanças. Pessoas assim tenderiam a dar importância a valores como conformidade, segurança e tradição, não priorizando aqueles como autodireção, estimulação e universalismo.

Em resumo, os cinco tipos de personalidade, em alguma medida, podem ser correlacionados com os valores humanos, ao menos como os operacionaliza $\mathrm{S}$. H. Schwartz (Sagiv, 2002). Apesar da importância deste modelo teórico (Ros, 2001), partiu-se de outro, que é mais parcimonioso e reúne informações sobre sua adequação métrica e capacidade explicativa no contexto brasileiro (Chaves, 2007; Gouveia, Albuquerque, Clemente \& Espinosa, 2002; Pimentel, 2004; Santos, 2008). A seguir se descreve este modelo, que será empregado para conhecer os valores humanos.

\section{VALORES HUMANOS BÁSICOS}

Gouveia (1998, 2003) tem proposto que os valores humanos podem ser explicados com base nas funções a que servem. Deste modo, propõe uma teoria funcional dos valores terminais, identificando duas funções principais: tipo motivador (materialista ou humanitário) e tipo de orientação (pessoal, central ou social). A combinação de tais funções permite derivar seis subfunções psicossociais que explicam a organização (estrutura) dos valores humanos. Tais subfunções, com valores específicos entre parênteses, são as seguintes: experimentação (emoção, prazer e sexo), realização (êxito, poder e prestígio), interação (afetividade, apoio social e convivência), normativa (obediência, religiosidade e tradição), existência (estabilidade pessoal, saúde e sobrevivência) e suprapessoal (beleza, conhecimento e maturidade).

Destarte, os valores específicos podem ser agrupados de acordo com um esquema 3 (tipo de orientação) x 2 (tipo de motivador) (Gouveia, 1998, 2003). Cada tipo de orientação abarca duas subfunções: valores pessoais (experimentação e realização), valores centrais (existência e suprapessoal) e valores sociais (interacional e normativo). Por outro lado, cada tipo de motivador concentra três subfunções: materialista (existência, realização e normativa) e humanitário (suprapessoal, experimentação e interacional). Este modelo parece explicar adequadamente a estrutura dos valores apresentada por Schwartz (2005), Schwartz e Bilsky (1987), conforme os achados de Gouveia (2003). Neste sentido, podem-se assumir como referência os padrões de correlações descritos por Sagiv (2002) entre os valores e os interesses (tipos de personalidade) vocacionais.

\section{VALORES E INTERESSES}

Os valores sugerem uma relação com os interesses vocacionais, pois, como afirma Holland (1997), eles são parte dos eventos que criam disposições ou tipos de personalidade para exibir um comportamento característico. Em muitas profissões é permitido atuar de acordo com os valores de cada um, entretanto, há profissões exercidas em ambientes em que predominam certos valores (Kasser \& Ahuvia, 2002). Um exemplo disso é encontrado na medicina, na qual predominam os valores sociais; já nas artes, valores estéticos são observados. Igualmente, se alguém não valoriza ou não acredita na salvação da alma, profissões como sacerdote, pastor ou rabino não se aplicam a ele (Giacaglia, 2003). A propósito do tipo de ofício (profissão ou estudo) que o indivíduo exerce e os valores que prioriza, existem alguns estudos na literatura.

Em pesquisa realizada com estudantes dos Estados Unidos $(n=180)$ e Singapura $(n=184)$, em que foram aplicados, entre outros instrumentos, o Questionário de Valores de Schwartz e o Inventário de Interesse Vocacional (UNIACT-R), Soh e Leong (2002) averiguaram que poucos foram os valores correlacionados com os interesses vocacionais. Concretamente, constataram que as pontuações no tipo de personalidade definido como empreendedor se correlacionaram diretamente com a importância atribuída aos valores dos tipos motivacionais poder $(r=$ $0,32, p<0,01)$ e realização $(r=0,23, p<0,01)$; poder também se correlacionou com o tipo de personalidade conversador $(r=0,23, p<0,01)$; e, finalmente, as pontuações no tipo motivacional de valor denominado de benevolência se correlacionaram com aquelas obtidas no tipo de personalidade social $(r=0,31, p<$ 0,01). Nenhuma outra correlação estatisticamente significativa $(p<0,01)$ foi destacada por estes autores.

No estudo de Furnham (1988), por exemplo, verificaram-se diferenças nas prioridades valorativas de estudantes de Medicina, Enfermagem e Psicologia. De acordo com esse autor, os estudantes de Psicologia, comparados aos demais grupos, valorizaram em maior medida um mundo em paz, amor maduro, imaginativo, intelectual e felicidade. Estudantes de Medicina, por outro lado, valorizaram mais uma vida excitante e lógica 
do que valores como um mundo em paz e educado. Finalmente, os estudantes de Enfermagem tenderam, por sua vez, a serem mais conservadores, valorizando, por exemplo, segurança familiar, salvação, alegria, limpeza, obediência, educação e autocontrole.

Chaves (2007) pesquisou as prioridades valorativas de advogados e músicos na cidade de João Pessoa (PB). Como poderia ser esperado, encontrou que os primeiros apresentavam uma orientação mais normativa (apoio social, obediência, religiosidade e tradição) e pautada em códigos e normas sociais do que os últimos. Estes, os músicos, por sua vez, foram mais predominantes em indicar como prioritários valores que enfocavam uma realização com independência, abertura a mudanças (acentuavam a autodireção, beleza, emoção e privacidade).

Diante do exposto, o objetivo específico desta pesquisa foi verificar que relações podem ser observadas entre os tipos de personalidade (interesses vocacionais) e as subfunções psicossociais dos valores humanos. Embora seja possível presumir que existam, é preciso que se comprovem a direção e magnitude destas correlações no contexto brasileiro, onde não se encontrou qualquer estudo a respeito.

\section{MÉTODO}

\section{Delineamento e hipóteses}

O presente estudo compreendeu um delineamento correlacional ex post facto, considerando dois conjuntos principais de variáveis: os valores humanos e os interesses vocacionais. Na Figura 2 a seguir são apresentadas as correlações que deveriam ser esperadas entre estes construtos, de acordo com o que foi observado por Sagiv (2002).

\begin{tabular}{|c|c|c|c|c|c|c|}
\hline \multirow[b]{2}{*}{ Funções Psicossociais } & \multicolumn{6}{|c|}{ Interesses Vocacionais } \\
\hline & $\mathbf{R}$ & $\mathbf{I}$ & $\mathbf{A}$ & $\mathbf{S}$ & $\mathbf{E}$ & $\mathbf{C}$ \\
\hline Experimentação & & & & & + & - \\
\hline Realização & & & & & + & \\
\hline Existência & & & & & & + \\
\hline Suprapessoal & & & . & & & + \\
\hline Interacional & & + & + & & - & - \\
\hline Normativa & & & & + & & \\
\hline Normativa & & & - & & & + \\
\hline
\end{tabular}

Figura 2. Hipóteses sobre a Relação dos Valores Humanos com os Interesses Vocacionais

\section{Amostra}

A pesquisa foi realizada contando com a participação de 307 jovens, estudantes do ensino médio, oriundos de três escolas públicas e três particulares de João Pessoa, PB. Estes apresentaram uma média de idade de 16 anos (amplitude de 14 a 26, $D P=1,60)$; em sua maioria eram do sexo feminino $(58,6 \%)$ e solteiros $(93,8 \%)$, considerando-se predominantemente de classe social média $(66,8 \%)$.

\section{Instrumentos}

Os participantes responderam a dois instrumentos principais:

Questionário dos Valores Básicos, QVB: compreende uma medida objetiva dos valores humanos, proposta por Gouveia (1998, 2003). Considera-se aqui a versão composta por 18 itens (valores) específicos, distribuídos eqüitativamente nas seis funções psicossociais anteriormente descritas. Estes itens são respondidos em escala de 7 pontos, com os seguintes extremos: $\mathbf{1}=$ Nada importante e $\mathbf{7}=$ Muito importante. Estudos prévios têm demonstrado a adequação psicométrica desta medida (Gouveia, 2003; Gouveia et al., 2002; Gouveia, Andrade, Milfont, Queiroga \& Santos, 2003).

Inventário de Interesse Vocacional, UNIACT: este, fundamentado no modelo teórico de Holland (1997), consta de 90 itens equiitativamente distribuídos em seis fatores principais: realístico (por exemplo, procurar defeitos em produtos; consertar um brinquedo), investigativo (por exemplo, aprender como o cérebro funciona; estudar biologia), artístico (por exemplo, ler sobre estilo literário de autores modernos; preparar desenhos para ilustrar uma revista de estórias), social (por exemplo, prestar primeiros socorros para uma pessoa ferida; ajudar pessoas em situação de emergência), empreendedor (por exemplo, dirigir uma pequena empresa; fazer negócios por telefone) e convencional (por exemplo, calcular os juros de um empréstimo; manter registro das contas/gastos). Cada item enfatiza alguma atividade relevante para caracterizar determinado trabalho; a tarefa do participante é avaliar quanto gosta do que expressa, utilizando para isso uma escala de três pontos, com os seguintes pesos: $\mathbf{1}=$ Não gosta, $\mathbf{2}=$ Indiferente e $\mathbf{3}=$ Gosta. Este instrumento foi adaptado para o contexto brasileiro por Gouveia et al. (no prelo). Estes autores comprovaram sua validade de construto por meio de análise fatorial confirmatória e observaram índices de consistência interna (Alfas de Cronbach) que variaram de 0,73 (empreendedor) a 0,82 (investigativo).

Além destes dois instrumentos, que foram contrabalanceados, apresentou-se uma lista com perguntas de natureza demográfica, a saber: sexo, idade, estado civil. Estas, invariavelmente, figuraram como a última parte a ser respondida. 


\section{Procedimento}

Os questionários foram aplicados em uma situação coletiva de sala de aula, sem a presença do professor. Uma única pessoa ficou responsável por aplicar todos os instrumentos. Os adolescentes foram solicitados a responder individualmente e de forma voluntária, sendo enfatizado que não existiam respostas certas ou erradas, interessando unicamente conhecer o seu modo de pensar e se comportar no diaa-dia. Pediu-se igualmente que não deixassem itens sem resposta. Em média, 25 minutos foram suficientes para concluir sua participação no estudo.

\section{RESULTADOS}

Para efetuar as correlações entre os valores humanos e os interesses vocacionais foram realizados alguns procedimentos prévios. No caso dos valores humanos, procedeu-se ao somatório da pontuação bruta de cada sujeito em cada valor básico, obedecendo ao critério de pertença a cada uma das seis subfunções psicossociais dos valores humanos. $\mathrm{O}$ resultado das somas era dividido pelo número de valores básicos que compunha a função correspondente. Este procedimento fornecia um valor ponderado para as seis subfunções psicossociais.

Algo similar foi feito para os interesses vocacionais. Os itens da escala (UNIACT) foram computados obedecendo à orientação fatorial proposta, composta por seis fatores (RIASEC). Ao final, cada uma das seis pontuações representava os fatores em questão. Os resultados da correlação entre estes dois construtos podem ser visualizados na Tabela 1.

Tabela 1. Correlação entre os Fatores do RIASEC e os Valores Humanos

\begin{tabular}{lccclll}
\hline Funções & $\mathbf{R}$ & $\mathbf{I}$ & $\mathbf{A}$ & $\mathbf{S}$ & $\mathbf{E}$ & $\mathbf{C}$ \\
\hline Experimentação & 0,04 & 0,00 & $\mathbf{0 , 1 3} *$ & 0,04 & 0,10 & 0,07 \\
\hline Realização & 0,02 & 0,07 & 0,04 & 0,06 & $\mathbf{0 , 1 5} * *$ & 0,10 \\
\hline Existência & 0,07 & 0,08 & 0,05 & 0,10 & 0,08 & $\mathbf{0 , 1 9} * *$ \\
\hline Suprapessoal & $\mathbf{0 , 1 8} *$ & $\mathbf{0 , 2 8} * * \mathbf{0 , 2 7} * *$ & $\mathbf{0 , 2 6} * *$ & $\mathbf{0 , 2 3} * *$ & $\mathbf{0 , 1 4}$ \\
\hline Interacional & 0,10 & 0,10 & $\mathbf{0 , 1 9} * *$ & $\mathbf{0 , 3 9} * *$ & $\mathbf{0 , 1 9} * *$ & $\mathbf{0 , 1 3}$ \\
\hline Normativa & 0,02 & 0,03 & 0,08 & $\mathbf{0 , 1 4} *$ & 0,11 & 0,01 \\
\hline
\end{tabular}

Significativamente estatístico para* $p<0,05, * * p<0,001$

Como é possível observar nesta tabela, as pontuações altas no tipo de interesse vocacional (tipo de personalidade) realístico apresentaram, surpreendentemente, correlação direta com os valores suprapessoais $(r=0,18 ; p<0,05)$. Por sua vez, os altos índices no interesse investigativo mostraram-se, como esperado, correlacionados positivamente com os valores suprapessoais $(r=0,28 ; p<0,001)$.

Pontuações altas no fator artístico mostraram-se correlacionadas positivamente com os valores suprapessoais ( $r=0,27 ; p<0,001)$, tal como havia sido hipotetizado. Por outro lado, não se confirmaram as hipóteses que indicavam que este interesse (tipo de personalidade) se correlacionaria negativamente com os valores normativos ( $r=0,08 ; p>0,05)$. Ademais, houve correlação positiva e significativa com valores interacionais $(r=0,19 ; p<0,001)$ e de experimentação $(r=0,13 ; p<0,05)$.

No que se refere ao interesse vocacional (tipo de personalidade) social, este apresentou um padrão de correlação de acordo com o esperado teoricamente. Encontraram-se correlações positivas com os valores suprapessoais $(r=0,26$; $p<0,001)$, normativos $(r=0,14 ; p<0,05)$ e, principalmente, interacionais $(r=0,39 ; p<0,001)$. Esta última correlação corrobora a hipótese inicial, entretanto a primeira não havia sido prevista. Esperava-se encontrar também uma correlação inversa entre os valores de experimentação e o interesse social, porém isto não foi observado $(r=0,04 ; p>0,05)$.

Para o tipo de personalidade (interesse) empreendedor, previu-se encontrar correlações positivas com os valores de experimentação e realização, porém negativas com aqueles suprapessoais. Apenas a segunda hipótese foi confirmada: realização $(r=0,15 ; p<0,001)$; os valores de experimentação não apresentaram correlação significativa com este tipo de interesse $(r=0,10 ; p>0,05)$. Contudo, empiricamente, foram observadas correlações, todas diretas, da pontuação no tipo empreendedor com os valores suprapessoais $(r=0,23 ; p<0,001)$ e interacionais $(r=0,19 ; p<0,001)$.

Finalmente, quanto ao tipo de personalidade convencional, das correlações teoricamente esperadas, uma positiva foi confirmada: aquela referente às pontuações neste tipo com os valores de existência ( $r$ $=0,19 ; p<0,001)$. Todavia, a correlação positiva encontrada entre este tipo de interesse vocacional e os valores suprapessoais $(r=0,14 ; p<0,05)$ não era esperada teoricamente. A correlação negativa esperada com os valores de experimentação não foi também verificada nesta amostra $(r=0,07 ; p>0,05)$. Além disso, outra correlação desde tipo de interesse foi observada, a saber, aquela que diz respeito aos valores interacionais $(r=0,13 ; p<0,05)$.

Em resumo, observa-se um padrão de correlação entre os tipos de personalidade (interesses vocacionais) e os valores humanos que, embora reproduza resultados prévios de pesquisa, evidencia 
alguma especificidade da associação entre tais construtos no contexto em que a pesquisa foi desenvolvida. Procura-se a seguir discutir mais pormenorizadamente os resultados encontrados.

\section{DISCUSSÃO}

Tendo-se em vista o objetivo do presente estudo conhecer a relação entre os valores humanos e os interesses vocacionais (tipos de personalidade) considera-se que este foi alcançado. Não obstante, algumas limitações potenciais podem ser levantadas nesta pesquisa, ainda que não invalidem os resultados anteriormente descritos. Um aspecto é a já comentada falta de estudos empíricos suficientes para formar um conjunto de conhecimentos acerca da questão vocacional. Ademais, a medida utilizada no presente estudo é, como na maioria dos estudos, de tipo verbal, fato que dificulta o estudo de variáveis sobre interesses vocacionais em pessoas analfabetas (Gusmão, 2004), limitando-se a amostra a pessoas com grau de instrução ao menos funcional. Seria, portanto, interessante em estudos futuros poder contar com medidas não-verbais, que possibilitassem cobrir uma amostra mais abrangente e diversificada, o que pode também ser levado a cabo com respeito aos valores humanos.

Diferentes amostras foram utilizadas neste estudo e no de Sagiv (2002), o qual fundamenta as hipóteses aqui tratadas, a saber: na presente pesquisa incluíramse jovens de idade média de 16 anos (entre 14 e 26 anos - estudantes brasileiros de ensino médio) ao passo que naquele realizado por Sagiv foi utilizada uma amostra com média de idade de 25 anos (entre 18 e 54 anos - clientes do serviço de orientação vocacional em Israel). Os resultados aqui encontrados são observados em uma época da vida em que, freqüentemente, os interesses se estão definindo; por outro lado, na amostra que fundamentou as hipóteses do estudo de Sagiv, as pessoas teriam uma melhor definição de seus interesses vocacionais. Salienta-se que, apesar desta diferença, algumas das correlações esperadas foram confirmadas.

Observou-se que valores suprapessoais, como beleza, conhecimento e maturidade, parecem independer dos tipos de interesse vocacional das pessoas; estão relacionados com quaisquer deles, sendo comparáveis inclusive com relação à magnitude das correlações. Isso é coerente com o que assinala Gouveia (2003) acerca desses valores, ao afirmar que eles seriam compatíveis tanto com orientações pessoais como sociais - isso no caso de se pretender dividir operacionalmente os tipos de personalidade vocacional em termos de orientação social. Assim, os tipos convencional, empreendedor e realístico teriam uma orientação pessoal, ao passo que interesses sociais, artísticos e investigativos teriam orientação social. Contudo, esta hipótese poderá ser contemplada melhor em estudos futuros.

Pode-se observar que as pontuações elevadas em valores interacionais, como apoio social, convivênciae afetividade, só não se correlacionam com pontuações em tipos de personalidade vocacional que exprimem maior aversão a ambientes sociais, nos quais se necessita interação maior com outras pessoas. Trata-se de profissões de habilidades mecânicas (realístico) e científicas (investigativo), como afirmava Holland (1997).

A correlação esperada entre interesse vocacional realístico e os valores normativos não foi corroborada. Este é outro aspecto que precisará ser considerado posteriormente, tendo-se em vista que em estudo realizado com uma amostra de universitários em final de curso havia sido corroborada (Gusmão, 2004). Tal resultado sugere que um envolvimento maior com a profissão implica em uma imbricação valorativa mais definida, não sendo o caso de estudantes de ensino médio, participantes desta pesquisa. Será, portanto, interessante contar em pesquisas futuras com a comparação entre estes dois tipos de grupo de envolvimentos distintos com a profissão (estudantes e profissionais).

Aquelas pessoas interessadas por profissões da área investigativa e artística priorizam atualizar seus conhecimentos sem ter interesses muito limitados quanto aos benefícios, de maneira que seus valores são algo mais que pessoais (suprapessoais). É unicamente a relevância dada à emoção o que distingue tais interesses vocacionais, o que pode ser observado por meio da correlação com valores como os de experimentação, ilustrando o aspecto nãoconvencional de pessoas de interesse artístico (Chaves, 2007). Trata-se de pessoas menos dadas a conformar-se a regras sociais, de maneira que o risco e a aventura lhes são atraentes. Além disso, pessoas com tais interesses vocacionais são definidas como abertas e interessadas no ambiente social, o que justifica pontuações elevadas em valores interacionais (por exemplo, convivência, apoio social).

No que tange ao tipo de interesse social, valores interacionais são mais provavelmente relacionados diretamente, de acordo com os resultados encontrados. Isso foi coerente com os achados de Soh e Leong (2002), que observaram correlação direta deste tipo de interesse (personalidade social) com o tipo motivacional de valores benevolência. Não obstante, 
também valorizam a religiosidade, a obediência e a tradição, isto é, valores normativos, que, segundo Gouveia (1998, 2003), também cumprem uma orientação social. Ajudar o próximo, neste caso, serviria à manutenção de uma situação social de equilíbrio, desejável a uma comunidade.

Os resultados referentes ao tipo de interesse empreendedor, o qual é típico de pessoas que se interessam por liderança ou persuasão, indicam que indivíduos que valorizam ser chefe de uma equipe ou tomar decisões e obter o que se propõem (por exemplo, poder e êxito, valores de realização; Soh e Leong, (2002)) tendem a apresentar pontuação alta em profissões com a característica citada. Interessam-se por convivência e apoio social, por exemplo, só que com um objetivo diferente dos demais tipos de interesse vocacional, pois o relacionamento com o próximo serviria ao alcance das metas pessoais. Este é um tipo de orientação tipicamente voltada para o êxito, o sucesso e a realização pessoal (Gouveia, 2003; Schwartz, 2005).

É compreensível que pessoas que apresentem interesse convencional apreciem assegurar estabilidade pessoal e sobrevivência, valores que cobrem a função de existência, pois são pessoas mais próximas do concreto, da busca material, ligadas a aspectos financeiros, fazendo sentido pensar na sua relação com a importância dada a tais valores. Contudo, este tipo de interesse não apresentou padrão correlacional tão claro. No caso dos valores normativos, a relação esperada era direta, por se tratar de pessoas mais conservadoras, como é o caso também daquelas com interesses realísticos e sociais. Neste sentido, o presente estudo ainda sugere que, posteriormente, considerando-se os resultados aqui descritos, outras pesquisas sejam realizadas contemplando, inclusive, diferentes realidades brasileiras.

Finalmente, diante dos resultados anteriormente descritos, poderia ser interessante realizar estudos longitudinais ou transversais em que se verificassem as correlações entre estas variáveis no decorrer do processo vocacional dos indivíduos. Todavia, longe de ser uma abordagem conclusiva da temática, a contribuição deste estudo está em fornecer a um campo ainda iniciante no Brasil (Gusmão, 2004) dados sobre a relação entre as prioridades valorativas de adolescentes e os seus interesses profissionais. Destarte, conhecer que valores orientam a escolha profissional das pessoas pode ser útil para entender mais acerca do contexto psicossocial em que se realiza esta escolha.

\section{REFERÊNCIAS}

Chaves, S. S. S. (2007). O bem-estar subjetivo e os valores humanos em músicos e advogados da cidade de João Pessoa. Tese de Doutorado não publicada, Programa Integrado de Doutorado em Psicologia Social, Departamento de Psicologia, Universidade Federal da Paraíba, João Pessoa.

Day, S. X. \& Rounds, J. (1998). Universality of vocational interest structure among racial and ethnic minorities. American Psychologist, 53, 728-736.

Farth, J., Leong, F. T. L. \& Law, K. S. (1998). Cross-cultural validity pf Holland's Model in Hong Kong. Journal of Vocational Behavior, 52, 425-440.

Ferreira, J. A. A. \& Hood, A. B. (1995). The development and validation of a Holland-Type Portuguese Vocational Interest Inventory. Journal of Vocational Behavior, 46, 119-130.

Furnham, A. (1988). Values and vocational choice: A study of value differences in medical, nursing and psychology students. Social Science and Medicine, 26, 613-618.

Giacaglia, L. E. A. (2003). Orientação vocacional por atividades. Uma nova teoria e uma nova prática. São Paulo: Thomson.

Gouveia, V. V. (1998). La natureza de los valores descriptores del individualismo y del colectivismo: Una comparación intra intercultural. Tese de Doutorado não publicada, Programa de Doutorado em Psicologia Social, Faculdade de Psicologia, Universidade Compluetense de Madri, Madri, Espanha.

Gouveia, V. V. (2003). A natureza motivacional dos valores humanos: evidências acerca de uma nova tipologia. Estudos de Psicologia, 8, 431-443.

Gouveia, V. V., Albuquerque, F. J., Clemente, M. \& Espinosa, P. (2002). Human values and social identities: A study in two collectivist cultures. International Journal of Psychology, 37, 333-342.

Gouveia, V. V., Andrade, J., Milfont, T. L., Queiroga, F. \& Santos, W. S. (2003). Dimensões normativas do individualismo e coletivismo: é suficiente a dicotomia pessoal vs. social? Psicologia: Reflexão e Crítica, 16, 223-234.

Gouveia, V. V., Meira, M., Gusmão, E. E. da S., Gouveia, R. S. V. \& Pessoa, V. S. (no prelo). O modelo RIASEC de interesses vocacionais: comprovação da hipótese de ordem circular. Em J. C. Alquieri (Org.), Avaliação Psicológica: uma perspectiva Iberoamericana.

Gusmão, E. É. da S. (2004). A hipótese da congruência vocacional: considerações acerca dos valores humanos e do bem-estar subjetivo. Dissertação de Mestrado, Programa de Mestrado em Psicologia Social, Departamento de Psicologia, Universidade Federal da Paraíba, João Pessoa.

Holland, J. L. (1996). Exploring careers with a typology. What we have learned and some new directions. American Psychologist, $51,397-406$.

Holland, J. L. (1997). Making vocational choices: A theory of vocational personalities and work environments. Englewood Cliffs: Prentice-Hall.

Kasser, T. \& Ahuvia, A. (2002). Materialistic values and well-being in business students. European Journal of Social Psychology, $32,137-146$. 
Levenfus, R. S. \& Soares, D. H. P. (2002). Orientação vocacional ocupacional. Novos achados teóricos, técnicos e instrumentais para a clínica, a escola e a empresa. Porto Alegre: Artmed.

Pimentel, C. E. (2004). Valores humanos, preferência musical, identificação grupal e comportamento anti-social. Dissertação de Mestrado não publicada, Programa de Pós-graduação em Psicologia Social, Departamento de Psicologia, Universidade Federal da Paraíba, João Pessoa.

Rokeach, M. (1973). The nature of human values. Nova York: Free Press.

Ros, M. (2001). Psicología social de los valores: Una perspectiva histórica. Em M. Ros \& V. V. Gouveia (Orgs.), Psicología social de los valores humanos: Desarrollos teóricos, metodológicos y aplicados (pp. 27-51). Madri: Biblioteca Nueva.

Sagiv, L. (2002). Vocational interests and basic values. Journal of Career Assessment, 10, 233-257.

Santos, W. S. (2008). Explicando comportamentos socialmente desviantes: uma análise do compromisso convencional $e$ afiliação social. Tese de Doutorado, Programa Integrado de
Doutorado em Psicologia Social, Departamento de Psicologia, Universidade Federal da Paraíba, João Pessoa.

Schwartz, S. H. (2005). Validade e aplicabilidade da teoria dos valores. Em A. Tamayo \& J. B. Porto (Orgs.), Valores e comportamentos nas organizações (pp. 56-95). Petrópolis, RJ: Vozes.

Schwartz, S. H. \& Bilsky, W. (1987). Toward a universal psychological structure of human values. Journal of Personality and Social Psychology, 53, 550-562.

Soh, S. \& Leong, T. L. (2002). Validity of vertical and horizontal individualism and collectivism in Singapore: Relationships with values and interests. Journal of Cross-Cultural Psychology, 33, $3-15$.

Weinrach, S. G. (1996). The psychological and vocational interest patterns of Donald Super and John Holland. Journal of Counseling and Development, 75, 5-16.

Recebido em 08/06/2006 Aceito em 10/08/2006

Endereço para correspondência : Valdiney V. Gouveia, Universidade Federal da Paraíba, CCHLA, Departamento de Psicologia, CEP 58051-900, João Pessoa-PB. E-mail: vgouveia@cchla.ufpb.br 